\title{
Grape disease detection using dual channel Convolution Neural Network method
}

\author{
Mawaddah Harahap ${ }^{1)^{*}}$, Valencia Angelina ${ }^{2)}$, Fenny Juliani ${ }^{3)}$, Celvin $^{4)}$, Oscar Evander ${ }^{5)}$ \\ 1)2)344)5) Universitas Prima Indonesia, Indonesia \\ ${ }^{1)}$ mawaddah@ unprimdn.ac.id, ${ }^{2)}$ valenciangln10@gmail.com, ${ }^{3)}$ fennyjuliani7@ gmail.com, \\ ${ }^{4)}$ celvinthamida1999@gmail.com, ${ }^{5}$ oscar.evander@gmail.com
}

Submitted : Apr 4, 2021 | Accepted : Apr 9, 2021 | Published : May 2, 2021

\begin{abstract}
Grapes are one type of fruit that is usually used to make grape juice, jelly, grapes, grape seed oil and raisins, or to be eaten directly. So far, checking for disease in grapes is still done manually, by checking the leaves of the grapes by experts. This method certainly takes a long time considering the extent of the vineyards that must be evaluated. To solve this problem, it is necessary to apply a method of detecting grape disease, so that it can help the common people to detect grape disease. This research will use the Dual-Channel Convolutional Neural Network method. The process of detecting grape disease using the DCCNN method will begin with the extraction of the leaves from the input image using the Gabor Filter method. After that, the Segmentation Based Fractal Co-Occurrence Texture Analysis method will be used to extract the features, color, and texture of the extracted leaves. The result is the number of datasets will affect the accuracy of the results of disease identification using the DCCNN method. However, more datasets will cause the execution process to take longer. Changes in the angle and frequency values in the Gabor method at the time of testing will reduce the accuracy of the test results. The conclusion of this study are the DCCNN method can be used to detect the type of leaf disease in grapes and the number of datasets will affect the accuracy of the results of disease identification using the DCCNN method.
\end{abstract}

Keywords: Digital Image, Dual-Channel Convolutional Neural Network, Gabor Filter Method, Grape Disease, Segmentation Based Fractal Co-Occurrence Texture Analysis Method.

\section{INTRODUCTION}

Grapes are one type of fruit that is usually used to make grape juice, jelly, grape seed oil and raisins, or to be eaten directly (Marhumah, Rahayu, \& Hayati, 2016). Seeing the economic potential and increasing public interest in grapes, this plant has high prospects to be cultivated and developed in other areas in Indonesia (Mardiyah, Basri, Yusuf, \& Hawalina, 2017). So far, checking for disease in grapes is still done manually, namely by checking the leaves of the grapes by experts. This method certainly takes a long time considering the extent of the vineyards that have to be evaluated.

Disease attack that appears on all grapes is Cercospora leaf spot. This disease is caused by a fungus that grows rapidly in humid conditions, and begins to be encountered from January when the rainfall is quite high. This disease causes the growth of the vine to be stunted because it attacks the shoots of the stems which then become dry. Apart from leaf spot, there also appears leaf rust disease caused by the fungus Physopella Ampelopidis and fake powder or Downy Mildew disease caused by Plasmopara Viticola. Symptoms of this disease are young leaves and shoots that become dry and fall off so that the growth of the grapes will be stunted. Like diseases caused by fungi in general, fake flour disease is also caused by high humidity in the air and soil due to high rainfall (SJ, Priantoro, \& Setiyati, 2013).

Similar research that has been done before, such as the analysis of pests in grapes with the Certainty Factor (CF) method approach based on mobile Android, where the system provides analysis of possible pests, especially in grapes, to determine the percentage of confidence, as well as treatment solutions based on facts. and the confidence value given by the user in answering questions during the consultation session when using this system (Hidayati P.I, 2018). However, the research carried out was in the form of an expert system application that used the question and answer concept and did not use visual images so that the results obtained were less accurate.

*name of corresponding author 
Other research uses the CCM method, where this method consists of four parts, first the color transformation structure for RGB image input is made, where green pixels are removed using a certain threshold value, then the image is segmented, and useful segments are extracted, finally the texture statistics are calculated. From the texture statistics, the presence of disease in plant leaves was evaluated (Narvekar, Kumbhar, \& Patil, 2014). Another study uses a united model based on multiple convolutional neural networks, where based on testing, it is found that the united model has an average validation accuracy of $99.17 \%$ and a testing accuracy of $98.17 \%$ (Ji, Zhang, \& Wu, 2020).

Other studies have used neural networks, which uses the thresholding method to obtain leaf area and the KMeans Clustering method to carry out the segmentation process of grape leaf disease, then the CNN method will be applied for classification of disease types (Saharia \& Kedia, 2016). The method has a disadvantage where the training process takes a long time. To increase the execution time of the CNN algorithm, it is necessary to modify the CNN method. This new modified method is called the Dual-Channel Convolutional Neural Network (DCCNN). The process of detecting grape diseases using the DCCNN method will begin with the extraction of the leaves from the input image using the Gabor Filter method. After that, the Segmentation Based Fractal CoOccurrence Texture Analysis method will be used to extract the features, colors, and textures of the extracted leaves. Finally, the DCCNN method will be applied to carry out the classification and detection process for the types of grape diseases. The DCCNN method was chosen to carry out the process of detecting this disease with the consideration that this method is still new (introduced in 2019) and this method is a development of the CNN method, where based on the tests carried out, this method has a better PSNR value and structural similarity than any other method (Chen, 2019).

\section{LITERATURE REVIEW}

Convolutional Neural Network (CNN) is a type of neural network that is often used for image data. CNN is used to detect and recognize certain objects in an image. CNN is included in the type of Deep Neural Network because of its deep network level and is widely implemented in image data. CNN has two methods; namely the classification using feedforward and the learning stage using backpropagation (Felix, Faisal, Butarbutar, \& Sirait, 2019). The way CNN works is that each neuron is presented in two dimensions. However, this CNN method has a weakness, namely, the training process is quite time-consuming (Ghoury, Sungur, \& Durdu, 2019). Therefore, this method was developed and resulted in a new method, the Dual Channel Convolution Neural Network. With this method, the results of the accuracy will be more accurate, and the training or testing process will be faster, where the process must go through clustering first (Sugiartha, Sudarma, \& Widyantara, 2016).

The Dual Channel Convolution Neural Network (DCCNN) uses two layers of the execution process, namely "deep channel and shallow channel", using 13 layers and 3 layers respectively; Shallow channels are used to restore the overall outline of the image, while deep channels are used to recover texture information. Therefore, the combination of these two channels can effectively improve training efficiency, improve feature installation capabilities, and reduce the computational complexity of the entire model. DC-CNN performs two cross-mixing on two sets of characteristics. First, the output of the two fully-connected layers is cross-connected and used as the next fully-connected layer input (Abhirawan, Jondri, \& Arifianto, 2017). Then, the next full connection layer is divided into two parts, the data in these two parts are mixed and connected, and the obtained feature vector is the final feature of the image. If the kernel size is larger than the input image, processing cannot be performed.

\section{METHOD}

Analysis of the work process of the Dual Channel Convolution Neural Network will be carried out using the help of a flowchart diagram. The work process of the Dual Channel Convolution Neural Network in detecting diseases in grapes is described in these flowcharts design.

Explanation of figure 1 below: First, input the type of grape leaf disease in the training process. After that, it will do an extraction with Gabor Filter method, then with SFCTA method, and last, with lab color moments method. The result is the program can gain texture and color extraction output. 


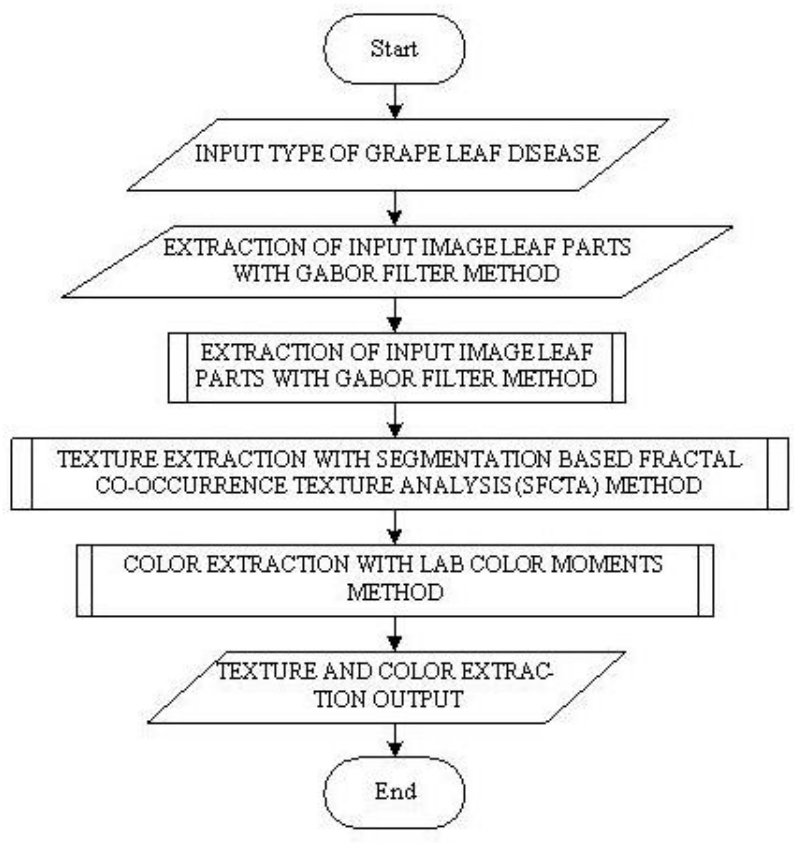

Fig. 1 Training Process Flowchart

The flowchart below is about testing process with using DCCNN execution.

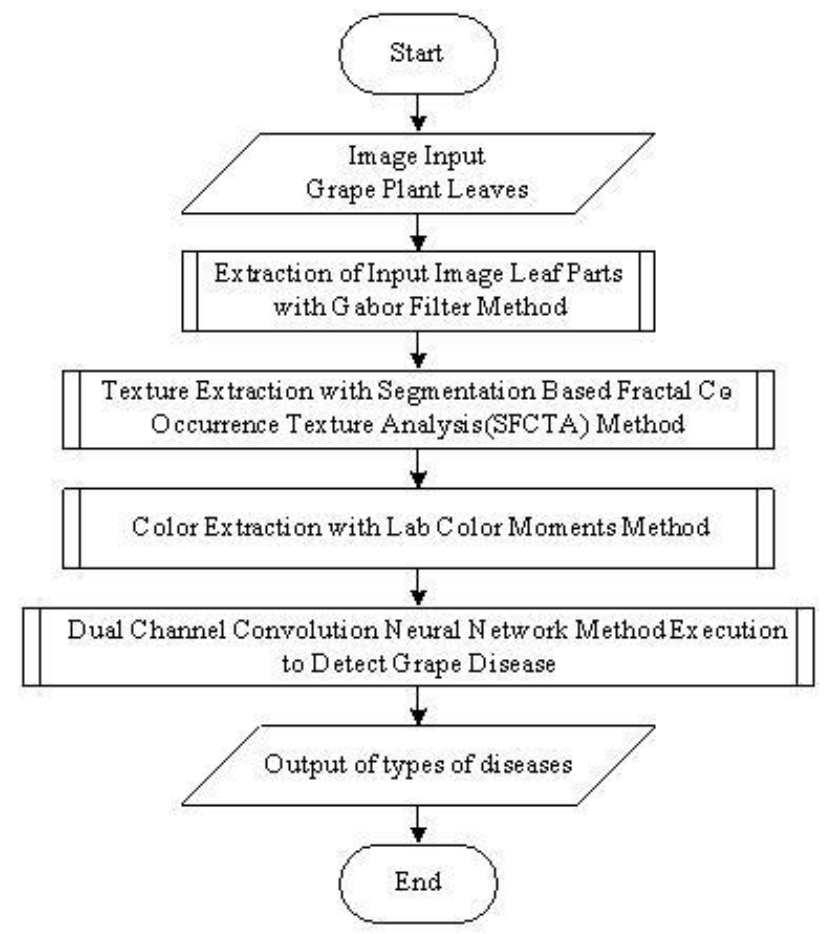

Fig. 2 Testing Process Flowchart

Explanation of figure 2 above: Input the image first. The same process will be happening again, the program will extract the image with gabor filter method, SFCTA method, and then lab color moments method. After that, there will be an execution using Dual Channel Convolution Neural Network Method to detect grape leaf diseases. The result is the program can detect the disease.

The extraction process using the Gabor Filter method (Leonardo, 2020) can be described by a flowchart below. 


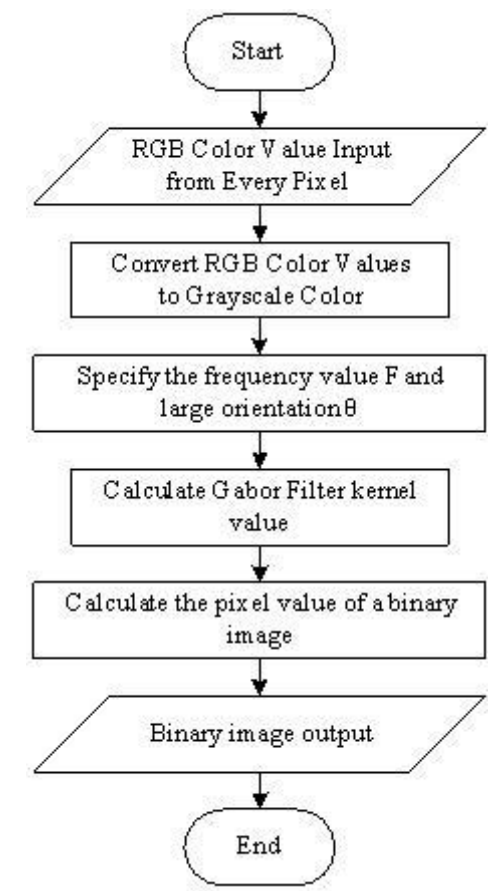

Fig. 3 Extraction Flowchart of the Input Leaf Image with the Gabor Filter Method

Explanation of figure 3 above: Put the value of RGB color from every pixel, then convert it to Grayscale color. Decide the frequency $(\mathrm{F})$ value and the $\theta$. Next, the process will calculate two things, Gabor Filter kernel value, and then the pixel value of a binary image. This step will have binary image as the output.

The process of texture extraction using the segmentation based fractal co-occurrence texture analysis (SFCTA) method can be described by a flowchart below.

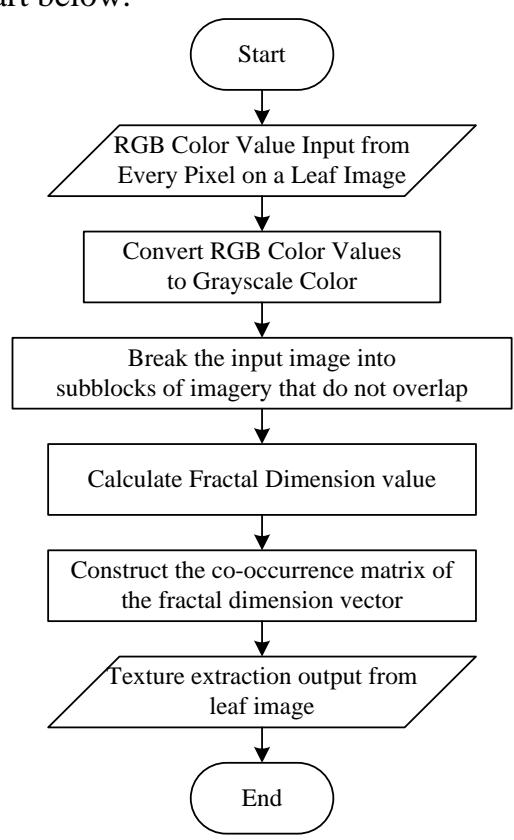

Fig. 4 Texture Extraction Flowchart using the Segmentation based Fractal Co-occurrence Texture Analysis (SFCTA) Method

Explanation of figure 4 above: Insert the value of RGB color, and convert it to Grayscale. Calculate the Fractal Dimension value. Next step, construct the co-occurence matrix from the vector of fractal dimension. Matrix result that obtained from the previous calculation is the output of texture extraction from the leaf image. 
The process of calculating color extraction using the Lab Color Moments method (Damayanti, Muntasa, Herawati, Yusuf, \& Rachmad, 2020) is described in this flowchart.

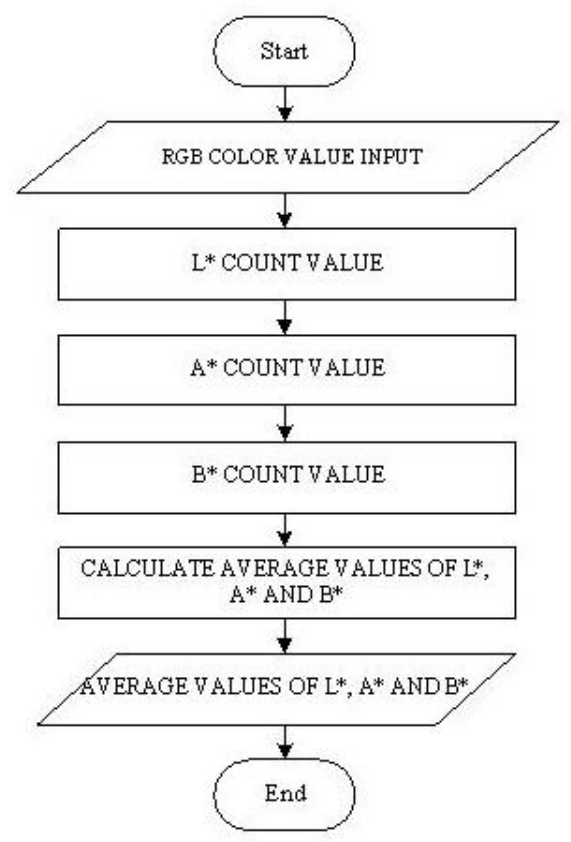

Fig. 5 Lab Color Moments Flowchart

Explanation: Input the RGB color. Count the $1^{*}$ value, in this step, use Illuminant D65 as the consideration of the standart daylight illuminant. Next, count the $a^{*}$, and then $b^{*}$. Calculate the mean value from $1^{*}, a^{*}$, and $b^{*}$.

Use Case Diagrams in modeling the functional requirements of the grapes leaf disease identification system.

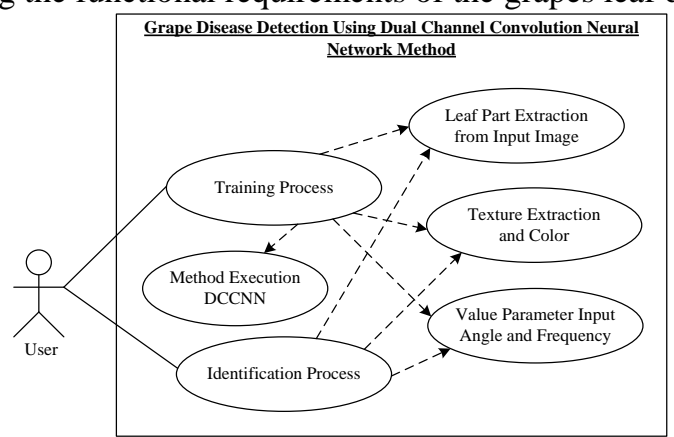

Fig. 6 Use Case Diagram of Grape Leaf Disease Detection Using the Dual Channel Convolution Neural Network

Explanation of figure 6 above: First, user will click the training button. And, the training process will begin. For the information, the system will save the result data of texture amd color extraction to the database. The identification process is used when user wants to know, if there is a disease on grape leaf or not. Only the training process, identification process, and parameter value of angle and frequency that have users input. Other than that, the system will takeover with an algorithm that has been made on this program.

\section{RESULT}

Testing are carried out using different types of images with different numbers of diseases in the images. The following are the results of the tests carried out. Diseases listed in the database can be seen in Table 1 . 
Table 1

Types of Diseases in the Database

\begin{tabular}{cll}
\hline \hline No. & Identity & Leaf Image \\
\hline 1 & Healthy Leaf & \\
2 & Black Measles \\
3 & $\begin{array}{l}\text { Black Rot(Sugiarti, } \\
4\end{array}$ \\
& Isariopsis Leaf Spot
\end{tabular}

The dataset will be processed using a frequency value $=0.707$ and a large angle $=30^{\circ}$. The testing process will be carried out by entering each of the 3 pictures for each disease. There are 75 data stored in the dataset for each type of disease and also for healthy leaves. The results of the identification process obtained can be seen in Table 2.

Table 2

Testing Results for Identification of Leaf Diseases in Grapes

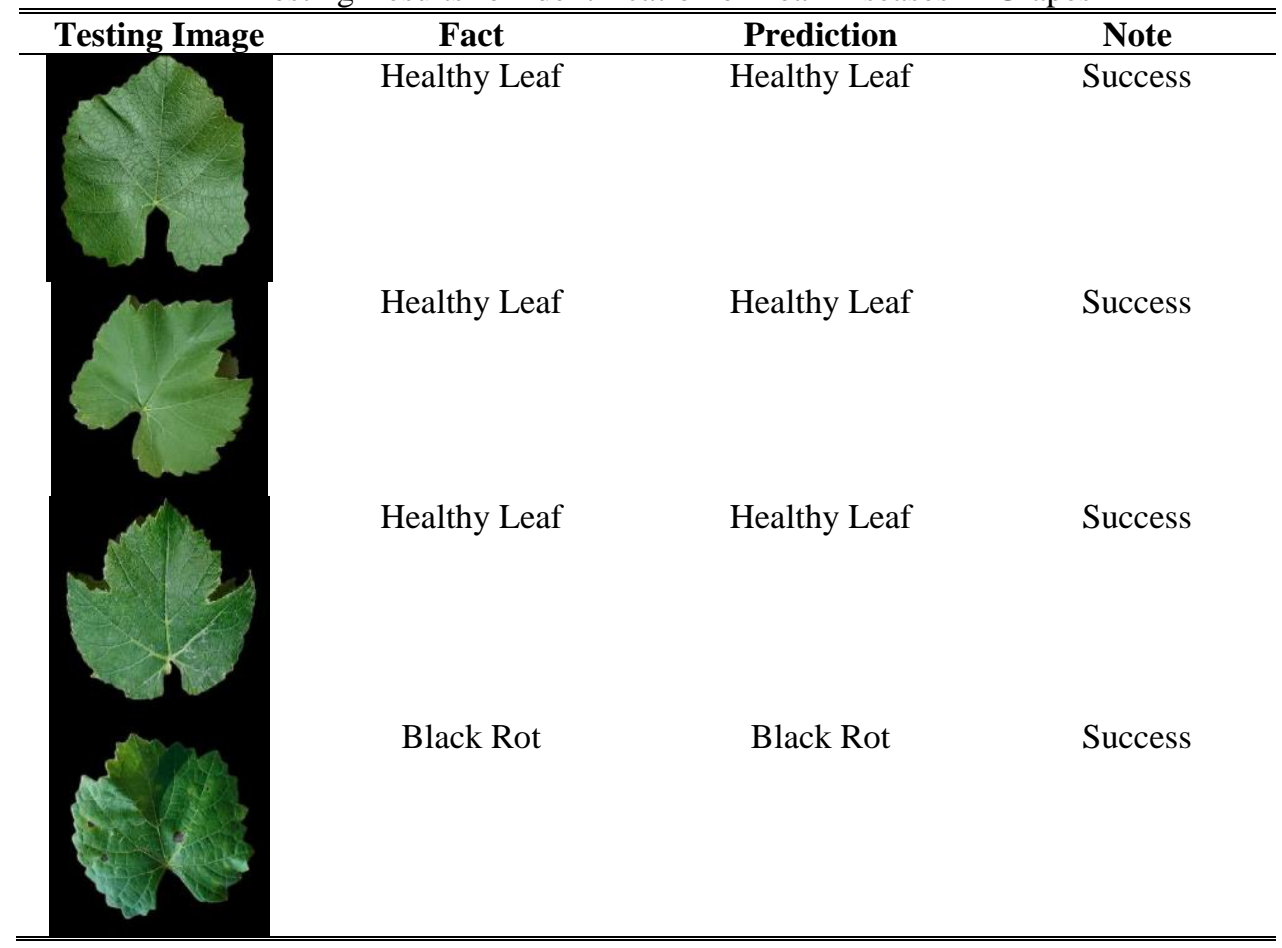




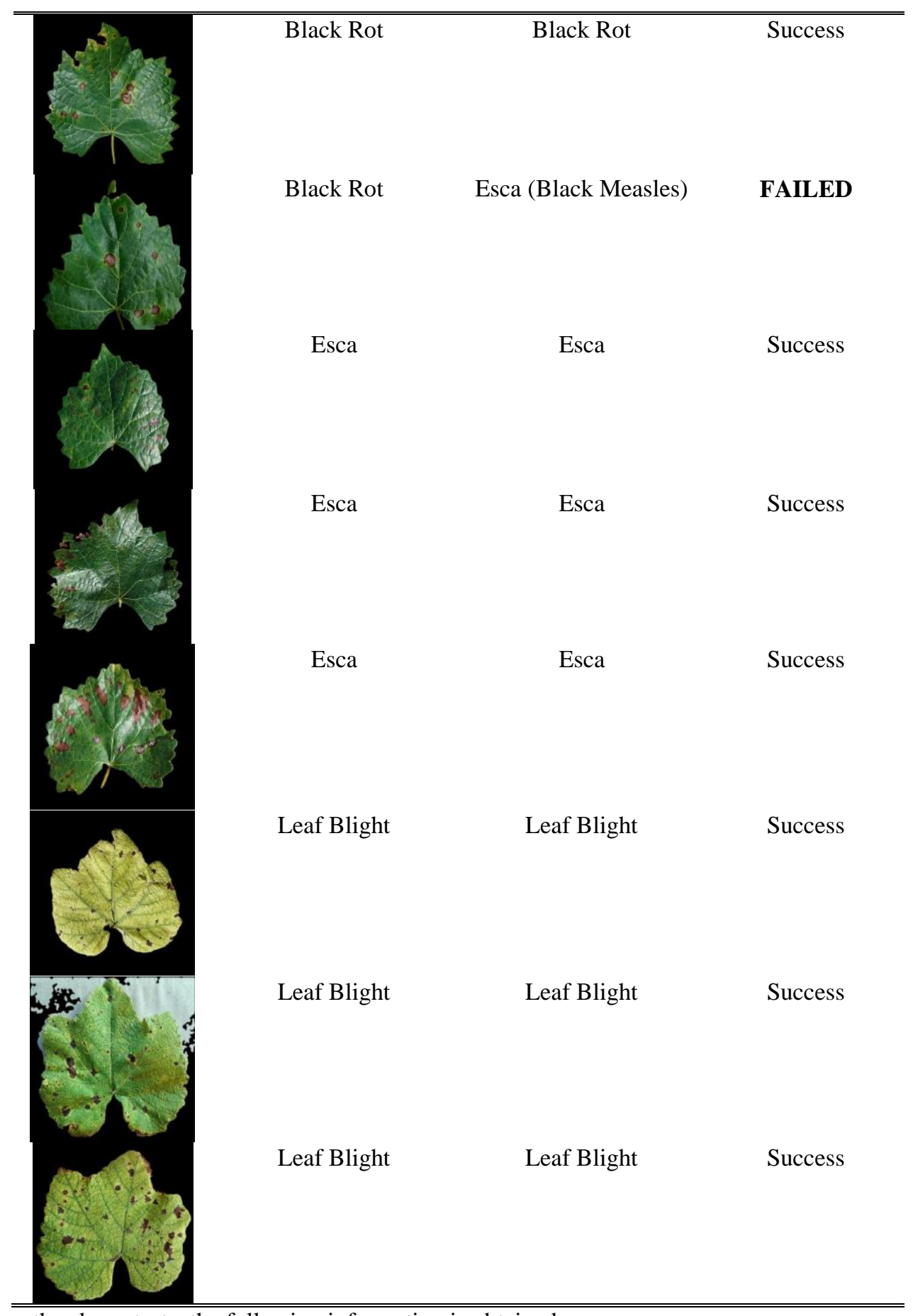

Based on the above tests, the following information is obtained:

Accuracy: $11 / 12 * 100 \%=91.67 \%$

Error: $1 / 12 * 100 \%=8.33 \%$

Other testing processes will be carried out using different input frequencies and angles to those carried out in the training process. The training process is carried out using the frequency value $\mathrm{F}=0.707$ and the angle $=30 \mathrm{o}$. This testing process will be carried out using variations in the frequency and angle values as follows:

1. $\mathrm{F}=0.707$ dan $\theta=60^{\circ}$.

The test is carried out using the same image as Table 2 above, the results obtained are as follows: 
Table 3

Testing

\begin{tabular}{ccc}
\hline Fact & Prediction & Note \\
\hline Healthy Leaf & Healthy Leaf & Success \\
Healthy Leaf & Healthy Leaf & Success \\
Healthy Leaf & Healthy Leaf & Success \\
Black Rot & Black Rot & Success \\
Black Rot & Black Rot & Success \\
Black Rot & Esca & FAILED \\
Esca & Esca & Success \\
Esca & Esca & Success \\
Esca & Esca & Success \\
Leaf Blight & Leaf Blight & Success \\
Leaf Blight & Leaf Blight & Success \\
Leaf Blight & Leaf Blight & Success \\
\hline
\end{tabular}

Based on the above tests, the following information is obtained:

Accuracy : $11 / 12 * 100 \%=91.67 \%$

Error: $1 / 12 * 100 \%=8.33 \%$

2. $\mathrm{F}=0.707$ dan $\theta=135^{\circ}$.

Table 4

Testing

\begin{tabular}{ccc}
\hline \hline Fact & Prediction & Note \\
\hline Healthy Leaf & Healthy Leaf & Success \\
Healthy Leaf & Healthy Leaf & Success \\
Healthy Leaf & Healthy Leaf & Success \\
Black Rot & Esca & FAILED \\
Black Rot & Black Rot & Success \\
Black Rot & Esca & FAILED \\
Esca & Esca & Success \\
Esca & Esca & Success \\
Esca & Esca & Success \\
Leaf Blight & Leaf Blight & Success \\
Leaf Blight & Leaf Blight & Success \\
Leaf Blight & Leaf Blight & Success \\
\hline \hline
\end{tabular}

Based on the above tests, the following information is obtained:

Accuracy: $10 / 12 * 100 \%=83.33 \%$

Error: $2 / 12 * 100 \%=16.67 \%$

3. $\mathrm{F}=0.044$ dan $\theta=30^{\circ}$.

Table 5

Testing

\begin{tabular}{ccc}
\hline \hline Fact & Prediction & Note \\
\hline Healthy Leaf & Healthy Leaf & Success \\
Healthy Leaf & Healthy Leaf & Success \\
Healthy Leaf & Healthy Leaf & Success \\
Black Rot & Healthy Leaf & FAIL \\
Black Rot & Healthy Leaf & FAIL \\
Black Rot & Healthy Leaf & FAIL \\
Esca & Esca & Success \\
Esca & Healthy Leaf & FAIL \\
Esca & Healthy Leaf & FAILED \\
Leaf Blight & Leaf Blight & Success \\
Leaf Blight & Leaf Blight & Success \\
Leaf Blight & Leaf Blight & Success \\
\hline \hline
\end{tabular}


Based on the above tests, the following information is obtained:

Accuracy: $7 / 12 * 100 \%=58.33 \%$

Error: $5 / 12 * 100 \%=41.67 \%$

Based on the testing process, the following information can be obtained:

1. The DCCNN method can be used to detect types of leaf disease in grapes.

2. The number of datasets will affect the accuracy of the results of disease identification using the DCCNN method. However, more datasets will cause the execution process to take longer.

3. By using the same frequency and angle values as the training process, the test accuracy value obtained is $91.67 \%$.

4. Changes in the angle and frequency values in the Gabor method at the time of testing will reduce the accuracy of the test results.

5. Changes in the frequency value used in the Gabor method at the time of testing will cause the type of disease to be difficult to detect, while changes in the angle value do not cause a drastic change in the accuracy of the test results.

\section{DISCUSSIONS}

The thing that will appear when first time running the Grape Disease Detection Application Using the Dual Channel Convolution is the 'Main' form. The Main Form can be seen in this picture below.

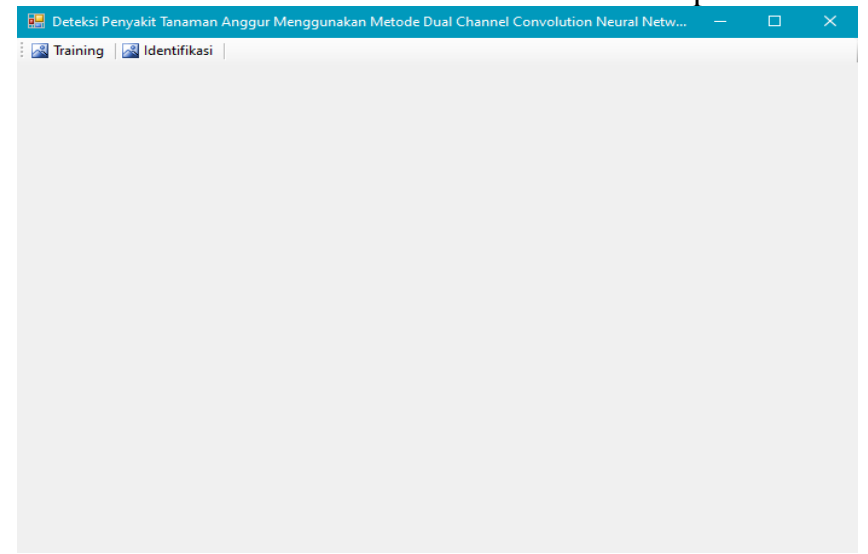

Fig. 7 Main Form

To add the dataset to the grape disease detection system, the user can click the Training menu so that the system will display the Training form as shown in Figure 8. Click the Save button to save the data entered into the database. After that, the user can identify the disease. The trick is to click the Identification menu so that the system will display the identification process form as shown in Figure 9.

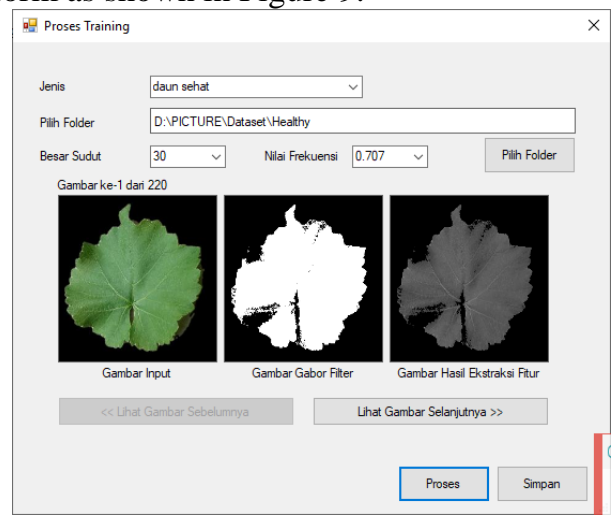

Fig. 8 Training Form After Processing 


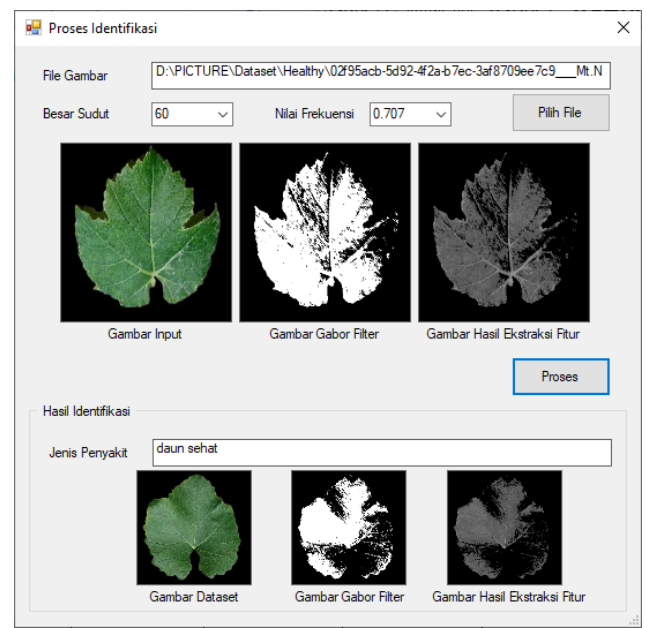

Fig. 9 Identification Process Form After Processing

\section{CONCLUSION}

From the previous discussion, the DCCNN method can be used to detect and recognize various types of leaf diseases in grapes by inputting a variety of leaf images. The accuracy of the results of disease detection by the DCCNN method depends on the number of datasets contained in the system. By using the DCCNN method, the test accuracy value obtained is $91.67 \%$ with the requirements for the angle and frequency values used are the same as the training process, and the frequency value in the Gabor method greatly influences the final result of the testing process while the angle value does not cause a significant change. With this way, the disease can be detected easier and faster than checking the leaf one by one.

\section{REFERENCES}

Abhirawan, H., Jondri, \& Arifianto, A. (2017). Pengenalan Wajah Menggunakan Convolutional Neural Networks (CNN). e-Proceeding of Engineering, 4(3), 4907-4916.

Chen, Y., Wang, J., Chen, X., Sangaiah, A. K., Yang, K., \& Cao, Z. (2019). Image super-resolution algorithm based on dual-channel convolutional neural networks. Applied Sciences (Switzerland), 9(11). https://doi.org/10.3390/app9112316

Damayanti, F., Muntasa, A., Herawati, S., Yusuf, M., \& Rachmad, A. (2020). Identification of Madura Tobacco Leaf Disease Using Gray-Level Co-Occurrence Matrix, Color Moments and Naïve Bayes. Journal of Physics: Conference Series, 1477(5). https://doi.org/10.1088/1742-6596/1477/5/052054

Felix, Faisal, S., Butarbutar, T. F. M., \& Sirait, P. (2019). Implementasi CNN dan SVM untuk Identifikasi Penyakit Tomat via Daun. 20(2), 117-134.

Ghoury, S., Sungur, C., \& Durdu, A. (2019). Real-Time Diseases Detection of Grape and Grape Leaves using Faster R-CNN and SSD MobileNet Architectures. (Icatces), 39-44.

Hidayati P.I. (2018). Analisis Hama pada Tanaman Anggur dengan Pendekatan Metode CF (Certainty Factor) Berbasis Mobile Android. SMATIKA Jurnal, 8(2).

Ji, M., Zhang, L., \& Wu, Q. (2020). Automatic grape leaf diseases identification via UnitedModel based on multiple convolutional neural networks. Information Processing in Agriculture, 7(3), 418-426. https://doi.org/10.1016/j.inpa.2019.10.003

Leonardo, L. (2020). Penerapan Metode Filter Gabor Untuk Analisis Fitur Tekstur Citra Pada Kain Songket. Jurnal Sistem Komputer dan Informatika (JSON), 1(2), 120. https://doi.org/10.30865/json.v1i2.1942

Mardiyah, Basri, Z., Yusuf, R., \& Hawalina. (2017). Pertumbuhan Tunas Anggur Hitam (Vitis vinifera L.) pada Berbagai Konsentrasi Benzylamino Purin dan Indolebutyric Acid. Jurnal Agroland, 24(3), 181-189.

Marhumah, S., Rahayu, T., \& Hayati, A. (2016). Perasan Macam Buah Anggur (Vitis Vinivera L.) Sebagai Penetralisir Merkuri (Hg) Dengan Metode Uval. Biosaintropis (Bioscience-Tropic), 2(1), 25-36.

Narvekar, P., Kumbhar, M. M., \& Patil, S. N. (2014). Grape Leaf Diseases Detection \& Analysis using CCM Method. International Journal of Computer Engineering and Applications, VI(Ii), 3365-3372.

Saharia, A., \& Kedia, Y. (2016). A Review paper on Artificial Neural Networks. 3(8), 65-71.

SJ, P. W. P., Priantoro, A. T., \& Setiyati, C. R. H. (2013). Terhadap Per Tumbuhan Tanaman Anggur ( Vitis Vinifera ). Penelitian, 19(1), 87-101. 
Sugiartha, I. G. R. A., Sudarma, M., \& Widyantara, I. M. O. (2016). Ekstraksi Fitur Warna, Tekstur dan Bentuk untuk Clustered-Based Retrieval of Images (CLUE). Majalah Ilmiah Teknologi Elektro, 16(1), 85. https://doi.org/10.24843/mite.1601.12

Sugiarti, L. (2017). Analisis Tingkat Keparahan Penyakit Karat Winaya Mukti Tanjungsari. Jagros, 1(2), 80-89. 